\title{
Prognostic factors analysis in EGFR mutation-positive non-small cell lung cancer with brain metastases treated with whole brain-radiotherapy and EGFR-tyrosine kinase inhibitors
}

\author{
HANGPING WEI ${ }^{1}$, MENG SU ${ }^{2}$, RUIFANG LIN ${ }^{2}$, HUIFANG LI $^{2}$ and CHANGLIN ZOU ${ }^{2}$ \\ ${ }^{1}$ Department of Medical Oncology, Dongyang People's Hospital, Dongyang, Zhejiang 322100; \\ ${ }^{2}$ Department of Radiation Oncology and Chemotherapy, The First Affiliated Hospital of Wenzhou Medical University, \\ Wenzhou, Zhejiang 325000, P.R. China
}

Received December 9, 2014; Accepted January 15, 2016

DOI: $10.3892 / \mathrm{ol} .2016 .4163$

\begin{abstract}
The survival time of non-small cell lung cancer (NSCLC) patients with brain metastases has been previously reported to be 6.5-10.0 months, even with systematic treatment. Patients that possess a certain epidermal growth factor receptor (EGFR) mutation alongside NSCLC with brain metastases also have a short survival rate, and a reliable prognostic model for these patients demonstrates a strong correlation between the outcome and treatment recommendations. The Cox proportional hazards regression and classification tree models were used to explore the prognostic factors in EGFR mutation-positive NSCLC patients with brain metastases following whole-brain radiation therapy (WBRT) and EGFR-tyrosine kinase inhibitor (EGFR-TKI) treatment. A total of 66 EGFR mutation-positive NSCLC patients with brain metastases were retrospectively reviewed. Univariate and multivariate analyses by Cox proportional hazards regression were then performed. The classification tree model was applied in order to identify prognostic groups of the patients. In the survival analysis, age, carcinoembryonic antigen (CEA) and status of the primary tumor were prognostic factors for progression free survival ( $\mathrm{P}=0.006,0.014$ and 0.005 , respectively) and overall survival $(\mathrm{P}=0.009,0.013$ and 0.009 , respectively). The classification tree model was subsequently applied, which revealed 3 patient groups with significantly different survival times: Group I, age
\end{abstract}

Correspondence to: Professor Changlin Zou, Department of Radiation Oncology and Chemotherapy, The First Affiliated Hospital of Wenzhou Medical University, 2 Fuxue Street, Wenzhou, Zhejiang 325000, P.R. China

E-mail: zcl19670115@163.com

Abbreviations: EGFR, epidermal growth factor receptor; NSCLC, non-small cell lung cancer; WBRT, whole-brain radiation therapy; EGFR-TKI, epidermal growth factor receptor-tyrosine kinase inhibitors

Key words: non-small cell lung cancer, brain metastases, epidermal growth factor receptor mutation-positive, classification tree model, prognostic factors
$<65$ years and CEA $\leq 10 \mu \mathrm{g} / \mathrm{ml}$; Group II, age $<65$ years and CEA $>10 \mu \mathrm{g} / \mathrm{ml}$ or age $\geq 65$ years and CEA $\leq 10 \mu \mathrm{g} / \mathrm{ml}$; and Group III, age $\geq 65$ years and CEA $>10 \mu \mathrm{g} / \mathrm{ml}$. The major prognostic predictors for EGFR mutation-positive NSCLC patients with brain metastases following WBRT and EGFR-TKI were age and CEA. In addition, primary tumor control may be important for predicting survival.

\section{Introduction}

Patients with non-small cell lung cancer (NSCLC) possess a high risk of developing brain metastases. The incidence rate of brain metastases for patients with lung cancer is $23-65 \%$ (1). Once intracerebral metastases develop, the prognosis is poor. The median survival time for patients with untreated brain metastases is only $\sim 1$ month $(2,3)$. The principle therapeutic modality for brain metastases is whole-brain radiation therapy (WBRT), and the median survival time following this treatment may increase to 4-6 months. Although therapies, including surgery, WBRT, stereotactic radiotherapy and systematic chemotherapy, are rapidly improving, the prognosis of patients with brain metastases from lung cancer remains poor, and the median survival time for patients remains at 6.5-10 months (4-7).

In 2004, the genes encoding the read code box of epidermal growth factor receptor (EGFR) were sequenced (8). In addition, the gene mutation status has been elucidated and is now widely used in clinical practice. As a result, the identification of the EGFR mutation and the introduction of treatment with EGFR-tyrosine kinase inhibitors (EGFR-TKI) has improved clinical outcomes (9). EGFR-TKI regimens have a good efficacy against brain metastases in NSCLC. In previous years, increasing efforts have been made to understand and use prognostic indicators in patients with brain metastases from NSCLC $(9,10)$. However, the prognostic factors of EGFR mutation-positive NSCLC patients with brain metastases following WBRT have not been studied extensively.

Based on the aforementioned considerations, the purpose of the present study was to analyze and assess the prognostic factors in EGFR mutation-positive NSCLC patients with brain metastases following WBRT and EGFR-TKI treatment, using 
the classification tree and Cox proportional hazards regression models.

\section{Materials and methods}

Patients. Between January 2005 and July 2014, 66 EGFR mutation-positive patients diagnosed with NSCLC were identified with brain metastases and treated at the Department of Radiation Oncology and Chemotherapy at The First Affiliated Hospital of Wenzhou Medical University (Wenzhou, China). The criteria for inclusion in the present retrospective study were as follows: i) All patients possessed a histopathological diagnosis of NSCLC, acquired by bronchial biopsy, fine needle aspiration biopsy or a surgical excision specimen; ii) all brain metastasis diagnoses were confirmed by head magnetic resonance imaging (MRI), contrast-enhanced computed tomography (CT) or positron emission tomography (PET)/CT scans; iii) the EGFR gene mutation was detected; iv) all patients were treated with EGFR-TKI until the disease progressed or the toxicity was intolerable; v) all patients were treated with WBRT (typically 30 gray units per 10 fractions); vi) all survival data were up to date on July 31,2014 ; and vii) the clinical data of all patients were complete. In total, 66 patients were available for the present analysis, 34 of which were males and 32 were females. The median age at the diagnosis of brain metastasis was 61 years old (range, 38-82 years). A total of $11(16.7 \%)$ patients possessed squamous cell lung carcinoma, while $55(83.3 \%)$ patients possessed adenocarcinoma.

Study design. The first section of the present study was a retrospective description regarding the recent therapeutic effects and long-term treatment effects observed in the patients. The second section of the study was a multivariate analysis that followed a univariate analysis, including 14 prognostic factors, using Cox proportional hazards regression. The final section of the study was a classification tree model.

The following variables were examined to determine the prognostic value for EGFR mutation-positive NSCLC patients with brain metastases following WBRT and EGFR-TKI treatment: i) Age at diagnosis of brain metastasis (for statistical purposes, the patients were classified into two age groups, $<65$ vs. $\geq 65$ years); ii) gender (male vs. female); iii) Eastern Cooperative Oncology Group performance status (ECOG PS; PS $\leq 2$ vs. $>2$ points); iv) histopathology (adenocarcinoma vs. squamous cell carcinoma); v) primary tumor node metastasis (TNM) stage (I-III vs. IV stage); vi) smoking (heavy vs. no/little); vii) history of pulmonary lesions radiotherapy (with vs. without); viii) history of pulmonary lesions surgical resection (with vs. without); ix) cisplatin-based chemotherapy (with vs. without); $\mathrm{x}$ ) number of brain metastases (single vs. multiple); xi) extracranial metastases (with vs. without); xii) carcinoembryonic antigen (CEA) levels at brain metastases diagnosis (for statistical purposes, the patients were classified into two groups, $\leq 10 \mu \mathrm{g} / \mathrm{ml}$ vs. $>10 \mu \mathrm{g} / \mathrm{ml}$ ); xiii) the status of the primary tumor (controlled vs. uncontrolled); and xiv) supportive chemotherapy (yes vs. no). No/little smoking was defined as a smoking index (SI) of $<200$ (11). SI was defined as the number of cigarettes smoked per day multiplied by the number of years smoked.
Evaluation. The therapeutic effects were evaluated using the RECIST 1.1 criteria (12). The therapeutic effects may be divided into complete response (CR), partial response (PR), stable disease (SD) and progressive disease (PD). The objective response rate (ORR) refers to the percentage of $\mathrm{CR}+\mathrm{PR}$ patients out of the total number of patients, and the disease control rate (DCR) refers to the percentage of $\mathrm{CR}+\mathrm{PR}+\mathrm{SD}$ patients out of the total number of patients. The long-term treatment effects were evaluated by recording the progression free survival (PFS) and overall survival (OS) rates. PFS was defined as the interval between the diagnosis of brain metastasis and the initial observation of PD or mortality from any cause. The OS was measured between the date of the diagnosis of brain metastasis and the time of the mortality of the patient or the deadline for the study (July 31, 2014).

Statistical analysis. The clinical data were described by median, frequency and percentage. Survival analyses for each prognostic factor were performed using the Kaplan-Meier method, using SPSS software version 19.0 (IBM SPSS; Armonk, NY, USA). The log rank test was used in statistical comparisons. The multivariate analysis was conducted using the Cox proportional hazard regression model. The classification tree model was subsequently applied. A P-value of $<0.05$ was considered to indicate a statistically significant difference.

\section{Results}

Statistical description. A total of 66 patients were analyzed. Of these, 3 patients achieved CR, 27 patients demonstrated a PR, 25 patients remained to possess SD and 11 patients developed a PD; therefore, the patients demonstrated an ORR of $45.5 \%(30 / 66)$ and a DCR of $83.3 \%$ (55/66). At the time of analysis, 5 patients (7.58\%) were alive, while 61 patients (92.42\%) had succumbed. The median PFS was 5.9 months (95\% CI, 4.2-8.8 months) and the median survival time of the entire cohort was 10.9 months (95\% CI, 8.7-14.1 months). The survival curve for EGFR mutation-positive NSCLC patients with brain metastases is shown in Fig. 1.

Survival analysis. In the univariate analysis, the following variables at the diagnosis of brain metastasis were significantly associated with an improved PFS and OS (P-values, respectively): Age $(0.008,0.028)$; CEA $(0.035,0.031)$; and the status of primary tumor $(0.015,0.026)$. The prognostic factors for PFS and OS in the univariate analysis are presented in Table I.

In the multivariate analysis, the prognostic predictors for PFS for EGFR mutation-positive NSCLC patients with brain metastases were age, CEA and status of the primary tumor $(\mathrm{P}=0.006,0.014$ and 0.005 , respectively). Age, $\mathrm{CEA}$ and status of the primary tumor were also predictive factors for OS ( $\mathrm{P}=0.009,0.013$ and 0.009 , respectively). The results of the prognostic factors for PFS and OS in the multivariate analysis are summarized in Tables II and III.

Classification tree model. Based on the clinical data, a classification and regression tree method $(13,14)$, a non-parametric regression method, was used. In addition, the method selected the automatic depth, which was length of the classification 
Table I. Prognostic factors for PFS and OS in univariate analysis.

\begin{tabular}{|c|c|c|c|c|c|}
\hline Prognostic factors & No. of patients & $\mathrm{PFS}^{\mathrm{a}}$ & PFS P-value & $\mathrm{OS}^{\mathrm{a}}$ & OS P-value \\
\hline \multicolumn{6}{|l|}{ Age, years } \\
\hline$<65$ & 40 & 8.7 & 0.008 & 13.2 & 0.028 \\
\hline$\geq 65$ & 26 & 3.4 & & 9.0 & \\
\hline \multicolumn{6}{|l|}{ Gender } \\
\hline Male & 34 & 6.9 & 0.481 & 10.1 & 0.929 \\
\hline Female & 32 & 4.6 & & 11.0 & \\
\hline \multicolumn{6}{|l|}{ ECOG PS } \\
\hline$\leq 2$ & 48 & 6.7 & 0.424 & 11.4 & 0.348 \\
\hline$>2$ & 18 & 3.2 & & 4.1 & \\
\hline \multicolumn{6}{|l|}{ Primary TNM stage } \\
\hline I-III & 15 & 3.3 & 0.314 & 6.2 & 0.125 \\
\hline IV & 51 & 7.1 & & 11.3 & \\
\hline \multicolumn{6}{|l|}{ Histopathology } \\
\hline Adenocarcinoma & 55 & 6.2 & 0.341 & 10.9 & 0.455 \\
\hline Squamous cell carcinoma & 11 & 5.7 & & 7.7 & \\
\hline \multicolumn{6}{|l|}{ Smoking } \\
\hline Heavy & 24 & 8.7 & 0.478 & 11.1 & 0.427 \\
\hline No/little & 42 & 4.6 & & 10.7 & \\
\hline \multicolumn{6}{|c|}{ Pulmonary lesions radiotherapy } \\
\hline With & 12 & 4.6 & 0.464 & 9.0 & 0.514 \\
\hline Without & 54 & 6.1 & & 10.9 & \\
\hline \multicolumn{6}{|c|}{ Pulmonary lesions surgical resection } \\
\hline With & 6 & 7.5 & 0.189 & 11.7 & 0.512 \\
\hline Without & 60 & 5.6 & & 10.9 & \\
\hline \multicolumn{6}{|l|}{ Cisplatin-based chemotherapy } \\
\hline With & 37 & 6.3 & 0.340 & 11.3 & 0.823 \\
\hline Without & 29 & 3.6 & & 9.9 & \\
\hline \multicolumn{6}{|l|}{ Brain metastases } \\
\hline Single & 22 & 6.0 & 0.538 & 11.2 & 0.715 \\
\hline Multiple & 44 & 5.4 & & 10.7 & \\
\hline \multicolumn{6}{|l|}{ Extracranial metastases } \\
\hline With & 35 & 6.2 & 0.747 & 11.0 & 0.441 \\
\hline Without & 31 & 4.4 & & 9.4 & \\
\hline \multicolumn{6}{|l|}{$\mathrm{CEA}, \mu \mathrm{g} / \mathrm{ml}$} \\
\hline$\leq 10$ & 27 & 9.3 & 0.035 & 16.0 & 0.031 \\
\hline$>10$ & 39 & 4.1 & & 8.7 & \\
\hline \multicolumn{6}{|l|}{ Primary tumor status } \\
\hline Uncontrolled & 15 & 2.7 & 0.015 & 6.7 & 0.026 \\
\hline Controlled & 51 & 7.1 & & 11.3 & \\
\hline \multicolumn{6}{|l|}{ Supportive chemotherapy } \\
\hline Yes & 24 & 5.4 & 0.450 & 11.6 & 0.731 \\
\hline No & 42 & 7.5 & & 10.6 & \\
\hline
\end{tabular}

aData measured in months. PFS, progression free survival; OS, overall survival; ECOG PS, Eastern Cooperative Oncology Group performance status; TNM, tumor node metastasis; CEA, carcinoembryonic antigen.

tree model. The terminal parent and child nodes were defined as 20 and 10, respectively. The adjusted significance level was defined as $\mathrm{P}<0.05$ in the splitting and merging of a tree branch. The nodes were combined into the same group where the significance level of the statistical difference between the survival distributions of two terminal nodes was $>0.05$. 
Table II. Multivariate analysis of prognostic factors for progression free survival.

\begin{tabular}{|c|c|c|c|c|c|}
\hline Variable & $\mathrm{B}$ & SE & Wald & $\operatorname{Exp}(B)$ & P-value \\
\hline Age, years & -0.721 & 0.261 & 7.664 & 0.486 & 0.006 \\
\hline $\mathrm{CEA}, \mu \mathrm{g} / \mathrm{ml}$ & -0.652 & 0.266 & 6.003 & 0.521 & 0.014 \\
\hline Primary tumor status & 0.872 & 0.312 & 7.807 & 2.391 & 0.005 \\
\hline
\end{tabular}

CEA, carcinoembryonic antigen; B, coefficient for the constant; SE, standard error; Wald, Wald $\chi^{2}$ test; Exp (B), exponentiation of B.

Table III. Multivariate analysis of prognostic factors for overall survival.

\begin{tabular}{|c|c|c|c|c|c|}
\hline Variable & $\mathrm{B}$ & SE & Wald & $\operatorname{Exp}(\mathrm{B})$ & P-value \\
\hline Age, years & -0.706 & 0.272 & 6.738 & 0.494 & 0.009 \\
\hline $\mathrm{CEA}, \mu \mathrm{g} / \mathrm{ml}$ & -0.674 & 0.271 & 6.178 & 0.510 & 0.013 \\
\hline Primary tumor status & 0.818 & 0.313 & 6.855 & 2.267 & 0.009 \\
\hline
\end{tabular}

CEA, carcinoembryonic antigen; B, coefficient for the constant; SE, standard error; Wald, Wald $\chi^{2}$ test; Exp (B), exponentiation of B.

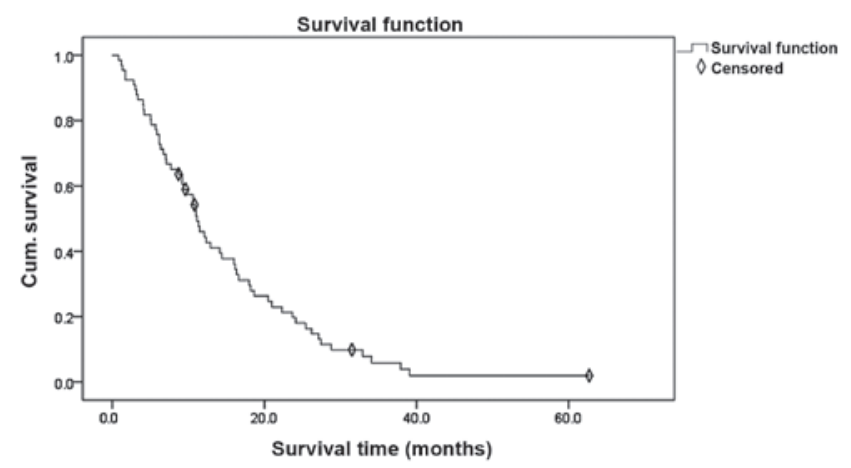

Figure 1. Survival curve of epidermal growth factor receptor mutation-positive non-small cell lung cancer patients with brain metastases. Cum., cumulative.

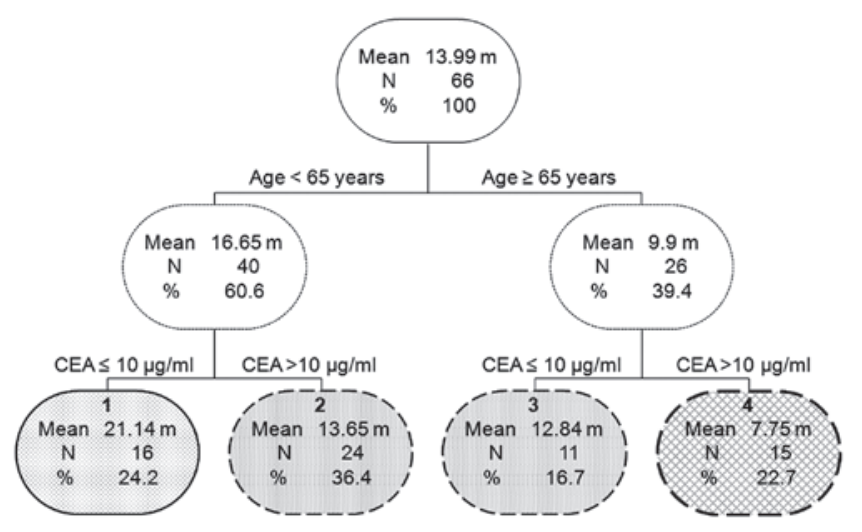

Figure 2. Classification tree model was used for EGFR mutation-positive non-small cell lung cancer patients with brain metastases following whole-brain radiation therapy and EGFR-tyrosine kinase inhibitors. EGFR, epidermal growth factor receptor; N, number of patients; CEA, carcinoembryonic antigen.

Following the application of the classification tree model, a survival tree was generated (Fig. 2), in which the first prognostic split occurred between patients aged $<65$ years vs. $\geq 65$ years.

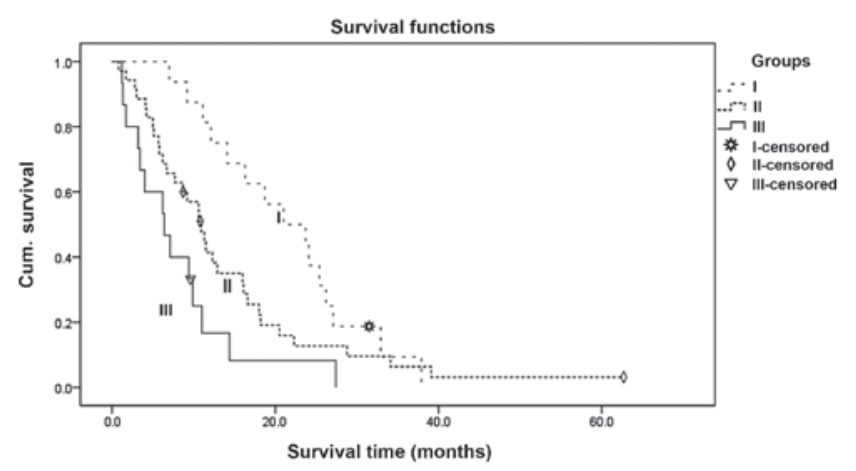

Figure 3. Survival curves of the three groups that were determined by classification tree analysis (log rank test; $\mathrm{P}=0.004)$. Cum., cumulative.

Within patients aged $<65$ years or $\geq 65$ years, the CEA level at the diagnosis of brain metastasis $(\leq 10 \mu \mathrm{g} / \mathrm{ml} \mathrm{vs.}>10 \mu \mathrm{g} / \mathrm{ml})$ became a dividing factor, finally resulting in four groups. No significant difference in the survival time between groups 2 and 3 was identified ( $\mathrm{P}=0.962$; Fig. 2). Therefore, groups 2 and 3 were combined. Finally, the patients were divided into three groups: Group I, age $<65$ years and CEA $\leq 0 \mu \mathrm{g} / \mathrm{ml}$; Group II, age $<65$ years and CEA $>10 \mu \mathrm{g} / \mathrm{ml}$ or age $\geq 65$ years and CEA $\leq 10 \mu \mathrm{g} / \mathrm{ml}$; and Group III, age $\geq 65$ years and CEA $>10 \mu \mathrm{g} / \mathrm{ml}$. The survival curves for the three groups that were determined by classification tree analysis are shown in Fig. 3 $(\mathrm{P}=0.004)$.

\section{Discussion}

The brain is one of the most common sites of metastasis in patients with lung cancer, and lung cancer is the most common intracranial metastatic tumor (15). The incidence of brain metastases in lung cancer is $20 \%$ at diagnosis and $40 \%$ at autopsy (16). In addition, brain metastases contribute to increased morbidity and mortality and herald a poor prognosis in patients with metastatic lung cancer (16). WBRT continues 
to be an important palliative treatment option for patients with brain metastases from NSCLC. In previous studies, WBRT combined with EGFR-TKI treatment was demonstrated to be a safe and effective treatment for EGFR mutation-positive NSCLC patients with brain metastases, with a median survival time of 7.7-13.0 months $(9,17,18)$. The median survival time in the present analysis was 10.9 months, which confirms these expectations. Predicting the survival time of patients is important, and the fact that a significant percentage of patients have a limited survival time suggests that accurate survival prediction models may assist in avoiding overtreatment (19,20).

In 1997, the Radiation Therapy Oncology Group established the prognostic scores recursive partitioning analysis (RPA) classification, which was the first prognostic scoring system for assessing the prognosis of patients with brain metastases (21-23). The detailed parameters of the model contained age, Karnofsky performance status (KPS), with or without extracranial metastases and the status of the primary tumor. Later, other established prognostic scores, including the basic score for brain metastases, systemic inflammatory response and graded prognostic assessment, were developed for the general population of patients with brain metastases.

Previous studies have demonstrated several prognostic factors in NSCLC patients with brain metastases. Gerosa et al (23) concluded that the performance status, age, extracranial metastases and primary tumor control caused a potential effect on survival. Zindler et al (24) revealed the prognostic value of performance status, age, absence of extracranial metastases, primary tumor site, gender and steroid response for OS. Rotin et al (25) indicated that the factors influencing survival were the number of brain metastases and KPS. Rades et al (26) revealed that the prior performance status, a younger age and the absence of extracranial metastases were associated with increased survival time. Therefore, in numerous published studies, age was commonly manifested as a prognostic factor. Additionally, patients having no PD in in the lung tumor was commonly mentioned as a prognostic factor.

The present Cox proportional hazards regression analysis of an EGFR mutation-positive NSCLC patient population with brain metastases confirmed that the prognostic implications of age $(<65$ years), CEA $(\leq 10 \mu \mathrm{g} / \mathrm{ml})$ and primary tumor control were favorable factors for survival time. Unlike previous studies, the clinical value of CEA in the prognosis of EGFR mutation-positive NSCLC patients with brain metastases was indicated to be extremely important. Recently, Fiala et al (27) showed that an increased level of CEA and CYFRA21-1 may be associated with a poor outcome for patients with NSCLC that are treated with erlotinib. These findings indicate that tumor biomarkers may be used for predicting the effect of therapy and the prognosis of patients.

Previous studies that investigated the prognostic factors of patients with brain metastases from NSCLC have indicated that traditional models focus on assessing the relative prognostic factors using the Cox proportional hazards regression model. A previous study indicated that, in combination with Cox proportional hazards regression, the survival tree method may aid prognostic analysis (28). To the best of our knowledge, none of the published prognostic classification models have involved EGFR mutation-positive NSCLC patients with brain metastases.
The present study aimed to use the Cox proportional hazards regression and classification tree models to analyze and explore prognostic factors in EGFR mutation-positive NSCLC patients, following WBRT and EGFR-EKI treatment. Age and CEA were the dominant prognostic factors identified in the classification tree model. Combining the aforementioned results of the Cox proportional hazard regression model, age ( $\geq 65$ years) and CEA ( $>10 \mu \mathrm{g} / \mathrm{ml})$ were considered to be adverse prognostic factors. In particular, the present analysis succeeded in splitting patients with brain metastases from EGFR mutation-positive NSCLC into three groups. The identification of prognostic groups between patients may provide prognostic information and serve as a basis of classification for future trials. In addition, the primary tumor status was indicated to be a prognostic factor in the Cox proportional hazards regression analysis. However, as the third dividing factor of the classification tree model, primary tumor control may be used a good predictor of prognosis, but may not be as reliable as age and CEA.

Regarding the present study, additional prospective studies are recommended to be performed in order to increase the accuracy of the results. Ideally, the sample size would have been larger. In conclusion, the major prognostic predictors of EGFR mutation-positive NSCLC patients with brain metastases following WBRT and EGFR-TKI were age and CEA. Age ( $\geq 65$ years) and CEA $(>10 \mu \mathrm{g} / \mathrm{ml})$ were considered to be the adverse prognostic factors. In addition, primary tumor control may be important for predicting survival.

\section{Acknowledgements}

The authors would like to acknowledge the following people, who have made the completion of the present study possible: Professor Changlin Zou, for vital guidance and support, and Mr. Lucheng Zhu, for encouragement and assistance.

\section{References}

1. Kong DS, Lee JI, Nam DH, Park K, Kim JH, Kim JG, Park JO and Park K: Prognosis of non-small cell lung cancer with synchronous brain metastases treated with gamma knife radiosurgery. J Korean Med Sci 21: 527- 532, 2006.

2. Zimm S, Wampler GL, Stablein D, Hazra T and Young HF: Intracerebral metastases in solid-tumor patients: Natural history and results of treatment. Cancer 48: 384-394, 1981.

3. Yang L, Parkin DM, Ferlay J, Li L and Chen Y. Estimates of cancer incidence in China for 2000 and projections for 2005. Cancer Epidemiol Biomarkers Prev 14: 243-250, 2005.

4. Gaspar L, Scott C, RotmaIl M, Asbell S, Phillips T, Wasserman T, McKenna WG and Byhardt R: Recursive partitioning analysis (RPA) of prognostic factors in three radiation therapy oncology group (RTOG) brain metastases trials. Int J Radiat Oncol Biol Phys 37: 745-751, 1997.

5. Lagerwaard FJ, Levendag PC, Nowak PJ, Eijkenboom WM, Hanssens PE and Schmitz PI: Prognostic factors in patients with brain metastases: A review of 1292 patients. Int J Radiat Oncol Biol Phys 43: 795-803, 1999.

6. Peng H, Ma M and Han B: Survival analysis of 1,742 patients with stage IV non-small cell lung cancer. Zhongguo Fei Ai Za Zhi 14: 362-366, 2011 (In Chinese).

7. Mekhail T, Sombeck M and Sollaccio R: Adjuvant whole-brain radiotherapy versus observation after radiosurgery or surgical resection of one to three cerebral metastases: Results of the EORTC 22952-26001 study. Curr Oncol Rep 13: 255-258, 2011.

8. Pao W, Miller V, Zakowski M, Doherty J, Politi K, Sarkaria I, Singh B, Heelan R, Rusch V, Fulton L, et al: EGF receptor gene mutations are common in lung cancers from 'never smokers' and are associated with sensitivity of tumors to gefitinib and erlotinib. Proc Natl Acad Sci USA 101: 13306-13311, 2004. 
9. Nieder N, Bremnes RM and Andratschke NH: Prognostic scores in patients with brain metastases from non-small cell lung cancer. Thorac Oncol 4: 1337-1341, 2009.

10. Abacioglu U, Caglar H, Atasoy BM, Abdulloev T, Akgun Z and Kilic T: Gamma knife radiosurgery in non small cell lung cancer patients with brain metastases: Treatment results and prognostic factors. J BUON 15: 274-280, 2010.

11. Yu PJ, Chen WG, Feng QL, Chen W, Jiang MJ and Li ZQ Association between CYP1B1 gene polymorphisms and risk factors and susceptibility to laryngeal cancer. Med Sci Monit 21: 239-245, 2015.

12. Eisenhauer EA, Therasse P, Bogaerts J, Schwartz LH, Sargent D, Ford R, Dancey J, Arbuck S, Gwyther S, Mooney M, et al: New response evaluation criteria in solid tumours: revised RECIST guideline (version 1.1). Eur J Cancer 45: 228-247, 2009.

13. Gass K, Klein M, Sarnat SE, Winquist A, Darrow LA Flanders WD, Chang HH, Mulholland JA, Tolbert PE and Strickland MJ: Associations between ambient air pollutant mixtures and pediatric asthma emergency department visits in three cities: A classification and regression tree approach Environ Health 14: 58, 2015.

14. Rovlias A, Theodoropoulos S, and Papoutsakis D: Chronic subdural hematoma: Surgical management and outcome in 986 cases: A classification and regression tree approach Surg Neurol Int 6: 127, 2015.

15. Kong DS, Lee JI, Nam DH, Park K, Kim JH, Kim JG, Park JO and Park K: Prognosis of non-small cell lung cancer with synchronous brain metastases treated with gamma knife radiosurgery. J Korean Med Sci 21: 527-532, 2006.

16. Ebert BL, Niemierko E, Shaffe K and Salgia R: Use of temozolomide with other cytotoxic chemotherapy in the treatment of patients with recurrent brain metastases from lung cancer. Oncologist 8: 69-75, 2003.

17. Arrieta O, Villarreal-Garza C, Zamora J, Blake-Cerda M, de la Mata MD, Zavala DG, Muñiz-Hernández S and de la Garza J: Long-term survival in patients with non-small cell lung cancer and synchronous brain metastasis treated with whole-brain radiotherapy and thoracic chemoradiation. Radiat Oncol 6: 166, 2011.

18. Ma S, Xu Y, Deng Q and Yu X: Treatment of brain metastasis from non-small cell lung with whole brain radiotherapy and gefitinib in a Chinese population. Lung Cancer 65: 198-203, 2009.
19. Lock M, Chow E, Pond GR, Do V, Danjoux C, Dinniwell R, Lea $J$ and Bezjak A: Prognostic factors in brain metastases: Can we determine patients who do not benefit from whole-brain radiotherapy. Clin Oncol (R Coll Radiol) 16: 332-338, 2004.

20. Xiang Z, Chen J, Zhang H, Shen L and Wei Q: Whole brain radiotherapy-based combined modality treatment of brain metastases from non-small cell lung cancer: A retrospective analysis of prognostic factors. Oncol Res Treat 38: 35-40, 2015.

21. Gaspar L, Scott C, Rotman M, Asbell S, Phillips T, Wasserman T, McKenna WG and Byhardt R: Recursive partitioning analysis (RPA) of prognostic factors in three radiation therapy oncology group (RTOG) brain metastases trials. Int J Radiat Oncol Biol Phys 37: 745-51, 1997.

22. Gaspar LE, Scott C, Murray K and Curran W: Validation of the RTOG recursive partitioning analysis (RPA) classification for brain metastases. Int J Radiation Oncol Biol Phys 47: 1001-1006, 2000.

23. Gerosa M, Nicolato A, Foroni R, Tomazzoli L and Bricolo A: Analysis of long-term outcomes and prognostic factors in patients with non-small cell lung cancer brain metastases treated by gamma knife radiosurgery. J Neurosurg (102Suppl): 75-80, 2005.

24. Zindler JD, Rodrigues G, Haasbeek CJ, De Haan PF, Meijer OW, Slotman BJ and Lagerwaard FJ: The clinical utility of prognostic scoring systems in patients with brain metastases treated with radiosurgery. Radiother Oncol 106: 370-374, 2013.

25. Rotin DL, Paklina OV, Kobiakov GL, Shishkina LV, Kravchenko ÉV and Stepanian MA: Lung cancer metastases to the brain: Clinical and morphological prognostic factors. $\mathrm{Zh}$ Vopr Neirokhir Im N N Burdenko 77: 24-28, discussion 29, 2013 (In Russian).

26. Rades D, Schild SE, Lohynska R, Veninga T, Stalpers LJ and Dunst J: Two radiation regimens and prognostic factors for brain metastases in non-small cell lung cancer patients. Cancer 110: 1077-1082, 2007.

27. Fiala O, Pessek M, Finek J, Benesova L, MinariK M, Bortlicek Z and Topolcan O: Predictive role of CEA and CYFRA21-1 in patients with advanced-stage NSCLC treated with erlotinib. Anticancer Res 34: 3205-3210, 2014.

28. Schilling C, Mortimer D, Dalziel K, Heeley E, Chalmers J and Clarke P: Using Classification and Regression Trees (CART) to identify prescribing thresholds for cardiovascular disease. Pharmacoeconomics: Nov 17, 2015 (Epub ahead of print). 